\title{
A startling 19,000-word thesis on the origin of AIDS: should the JME have published it?
}

\author{
Raanan Gillon Imperial College Health Service and St Mary's Hospital Medical School, London University
}

In December 1991 a startling 19,000 monograph was published by the Australian University of Wollongong (1). It was the final version of a paper arguing that AIDS is the result of 'a low technology error ... the greatest yet made by the human race'. A version of the paper was first written at the end of 1987 by Louis Pascal, rigorously following up ideas he had heard expressed on a radio programme by an American doctor, Eva Snead. He sent it to various AIDS researchers and others and submitted it, in one version or another, to several journals including the Lancet, Nature, New Scientist and the Fournal of Medical Ethics, all of which rejected it - though this journal encouraged him to submit a revised and radically shorter version, summarising his scientific arguments and concentrating on the ethical issues that arose.

$\mathrm{Mr}$ Pascal's paper argues, in a nutshell, that AIDS is an iatrogenic disease, ie caused by doctors. The Human Immunodeficiency Virus, HIV, he believes, was transmitted into the human race from monkeys as a result of oral 'vaccination' programmes against poliomyelitis carried out in Africa at the end of the 1950s. The live polio virus used in the vaccine was grown in monkey kidney tissue cultures and it is Louis Pascal's thesis that the monkey kidneys used were infected with Simian Immunodeficiency Virus, SIV, a retrovirus very similar to HIV, and that the SIV thus contaminated the oral polio virus vaccine. As a result of mass vaccination, and perhaps especially importantly, vaccination of infants with their relatively immature immune systems, some of the humans vaccinated became infected with the SIV, and thus the first human hosts of HIV.

As I explained to Mr Pascal when he first submitted the paper, while I found the thesis interesting and potentially important, the function of the Fournal of Medical Ethics is to discuss ethical issues, not to publish original scientific hypotheses. However, there were potentially important ethical issues embedded in the story, including, perhaps, the difficulty he had had in finding a scientific journal to publish his paper. I asked him to cut the paper down to 3,500 words, briefly outlining his substantive thesis and discussing the ethical issues raised by the rejections of his paper. I also suggested that he might wish to consider the ethical issues that would be raised by publication of material that might well dissuade large numbers of people from having their infants vaccinated against polio and perhaps against other infections.

The paper came back, even longer than the original, $\vec{\infty}$ with the challenging ethical argument that though it was $-\vec{\omega}$ much too long I might well help to save millions of lives $\dot{\omega}$

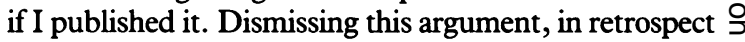
perhaps rather too swiftly, by explaining that I couldn't publish a 19,000 word paper even if I thought - and I was not persuaded - that it would save millions of lives, I wrote asking him again to shorten the paper, preferably as originally requested, but offering a maximum of 7,500 words in view of his assurances that it was impossible to cut it to a good paper of 3,500 words. But this too was rejected and $\mathrm{Mr}$ Pascal decided to offer the paper elsewhere. In addition to its forthright condemnation of the scientists involved in the original trials and the scientists sent his paper who failed to take up its themes, the current paper is vigorous in its condemnation of the rejecting editors - who are 'entirely culpable', 'sending who-knows-how-many present and future people to a horrible and pointless death', without any 'conceivable excuse' and apparently 'under the impression that they have an absolute right to reject anything they like regardless of the consequences'.

Well the monograph is now published, and available free of charge in hard copy or Macintosh computer disc (1) and this editorial is written primarily with the intention of helping to make its availability known, for its substantive thesis seems important enough to require consideration. If it were true it would certainly have very important implications, not least for AIDS scientists, for makers of live vaccines grown in monkey tissues (or indeed in tissues of any other species), and doubtless too for lawyers specialising in allegations of medical $\mathrm{C}$ negligence.

The thesis of Mr Pascal's paper is essentially based on 0 circumstantial evidence, but an impressive amount of it. It starts with an account of widespread contamination with the famous HeLa cervical cancer cell line of various 0 other human cell cultures used in cancer research, and of alleged suppression of information about this contamination (2). It goes on to argue that something similar is happening to Pascal's thesis. He argues that even though worries about contamination with foreign viruses had been expressed when trials of live oral polio vaccine were first proposed they went ahead anyway, starting in 1958 in Central Africa, in what are now Rwanda, Burundi and 
Zaire (3). (Mr Pascal does not mention this, but presumably thousands of lives and limbs were saved as a result). In 1959 Albert Sabin reported 'an unidentified non-poliomyelitis cytopathogenic virus' contaminating that first batch of vaccine used in the Belgian Congo and Ruanda-Urundi (4); and in the 1960s the first contaminant monkey virus to be identified, SV-40, was isolated both from polio vaccine batches and from people who had been vaccinated (5) thus establishing that polio vaccines could indeed be contaminated by other viruses, which could be passed on to the humans vaccinated. In 1985 the first of the SIVs was found in rhesus monkeys, and later SIVs were found in cynomolgus and in African green monkeys. All three species are used to make polio vaccine. Central Africa, including the countries where those first mass polio immunisation campaigns occurred, has very high rates of AIDS; and Mr Pascal points out that one of the earliest HIV-positive blood samples was taken in Kinshasha in 1959; the polio immunisation campaign had been active in Kinshasha (then Leopoldville) in 1958, using that first batch of vaccine.

All this is impressively coherent and entirely consistent with the causal thesis propounded by $\mathrm{Mr}$ Pascal. But consistency does not show causality. Moreover there have been some counterarguments in the scientific literature, as Mr Pascal scrupulously acknowledges - though he dismisses them scathingly. These include the deliberations of a World Health Organisation group of experts in 1985 (6), the assessment of a British professor of microbiology in 1986 (7) of the WHO specialists' conclusions as 'reassuring', and a Japanese study (8) producing negative tests for SIV in the kidneys of monkeys known to have the infection, negative attempts to infect known 'clean' tissue cultures of monkey kidney cells with SIV, and negative tests for SIV in representative polio vaccine stocks and also in 190 recipients of live oral polio vaccine.

Mr Pascal rebuts these various objections at length, claiming that the WHO report and the Japanese study 'are clear attempts at whitewash'. Among his many counterarguments are that the tests relied on by the WHO group are now known to be inadequate; that far too few batches of live polio vaccine were tested; that of course oral transmission of SIV to humans can be expected to be a very rare event; but that is no argument that it did not happen - and negative testing of a few hundred recipients of polio vaccine certainly does not show that it didn't. Nor is he impressed with negative efforts to infect kidney cells with SIV - the point is, do lymphocytes, which can be infected, occur in kidney cell tissue cultures? According to the WHO group, monkey cell cultures 'would be expected to contain few, if any, T-lymphocytes' - 'which is it?', challenges Mr Pascal, none or few?, pointing out that in the Japanese study the researchers reported 'a few lymphocytes in primary kidney cell cultures' (7).
It is not the role of the Fournal of Medical Ethics to opine on the truth or falsity of Mr Pascal's thesis. What does seem clear is that it is an important and thoroughly argued one and ought to be taken seriously by workers in the AIDS field.

In addition Pascal raises, though does not discuss analytically, a variety of ethical issues. He focuses on the rejection of his paper by several scientific journals. Time will show whether his thesis gains scientific acceptance. Most in science publishing would say that one should never give up submitting one's papers if one believes one has something important to say, and certainly a half dozen rejections need not give rise to assumptions of conspiracy to gag the truth. As for whether the fournal of Medical Ethics should have published the full 19,000word paper, I and the editorial board are clear that this would have been inappropriate - but we encouraged $\mathrm{Mr}$ Pascal to shorten and modify it so that it might be suitable. If not, we decided that an editorial outlining the issues would be our contribution to the non-suppression of unpalatable but possibly true, and if true important, hypotheses lying at the fringes of our field of interest.

\section{References and notes}

(1) Pascal L. What happens when science goes bad. The corruption of science and the origin of AIDS: a study in spontaneous generation. University of Wollongong Science and Technology Analysis Research Programme. Working Paper No 9, 1991 Dec. Available free of charge from: STA Working Papers, Department of Science and Technology Studies, University of Wollongong, PO Box 1144, Wollongong NSW 2500, Australia; fax +61-42-213452.

(2) Pascal cites and summarises a book by Michael Gold on this topic: A conspiracy of cells: one woman's immortal legacy and the medical scandal it caused. Albany: State University of New York Press, 1986. According to Pascal this is 'one of the most important works of our time' and should be widelyrequired reading.

(3) Courtois G, Flack A, Jervis G A, Koprowski H, Ninane G. Preliminary report on mass vaccination of man with live attenuated poliomyelitis virus in the Belgium Congo and Ruanda-Urundi. British medical journal, 1958; ii: 187-190.

(4) Sabin A B. Present position of immunisation against poliomyelitis with live virus vaccines. British medical journal, 1959; 1: 663-680.

(5) Sweet B H, Hilleman M R. The vacuolating virus, SV40. Proceedings of the Society of Experimental Biology and Medicine, 1960; 105: 420-427. Pascal also cites further evidence for this claim in his reference (13).

(6) Anonymous. T-lymphotropic retroviruses of non-human primates. WHO informal meeting. Weekly epidemiological record 1985 Aug 30; 35: 269-270.

(7) Zuckerman A J. AIDS in primates. British medical journal, 1986; 292: 158.

(8) Ohta Y, Tsujimoto H, Ishikawa K, et al. No evidence for the contamination of live oral poliomyelitis vaccines with simian immunodeficiency virus [letter]. AIDS 1989; 3: 183185. 